\title{
Ixodid ticks on dogs in southern Mozambique
}

\author{
L. NEVES ${ }^{1}$, SONIA AFONSO ${ }^{1}$ and I.G. HORAK ${ }^{2}$
}

\begin{abstract}
NEVES, L., AFONSO, SONIA \& HORAK, I.G. 2004. Ixodid ticks on dogs in southern Mozambique. Onderstepoort Journal of Veterinary Research, 71:279-283

The objective of this study was to determine the species and distribution of ticks infesting domestic dogs in southern Mozambique. To this end 89 collections were taken from dogs and the geographic coordinates of the localities at which they were made noted. Fifty-eight of these collections were from animals in the city of Maputo and 16 from animals at rural settlements close to Maputo. A further 15 collections were made from dogs in rural environments north of Maputo. Ten ixodid tick species, of which one was only identified to genus level, were recovered. Rhipicephalus sanguineus was the most numerous of the ten species, and its prevalence and intensity of infestation were significantly higher on city dogs than on rural dogs $(P<0.01)$, whereas the converse was true for Haemaphysalis leachi $(P<0.01)$. Including the city of Maputo, the exact localities at which nine tick species were collected, were recorded
\end{abstract}

Keywords: Dogs, ixodid ticks, Maputo, Mozambique

\section{INTRODUCTION}

In her publication on the ticks of domestic stock in Mozambique (then known as Portuguese East Africa) Theiler (1943) listed 13 species of ixodid ticks and mentioned that 11 of these could infest dogs. However, specimens of only three of these species, namely Haemaphysalis leachi, Rhipicephalus appendiculatus and Rhipicephalus simus appeared to actually come from dogs in Mozambique, while the rest were probably extrapolations from South African data. Some years later Dias $(1960,1993)$ listed the ticks infesting domestic and wild animals in Mozambique, and recorded 12 species on dogs. Nevertheless, he expressed doubts concerning the

\footnotetext{
1 Veterinary Faculty, University Eduardo Mondlane, Maputo, Mozambique

2 Faculty of Veterinary Science, University of Pretoria, Onderstepoort, 0110 South Africa

Accepted for publication 29 March 2004-Editor
}

validity of some of these species, and two of them, namely Haemaphysalis humerosoides and Rhipicephalus reichnowi are now considered synonyms of $H$. leachi and Rhipicephalus planus, respectively (Camicas, Hervy, Adam \& Morel 1998; Walker, Keirans \& Horak 2000).

In north-eastern KwaZulu-Natal Province, South Africa, a region adjoining the southern border of Mozambique, Horak, Emslie \& Spickett (2001) recovered seven species of ixodid ticks from dogs belonging to persons in rural communities. Adult $H$. leachi followed by immature Amblyomma hebraeum and adult $R$. simus were the most numerous of these. In the Kruger National Park, South Africa, to the west of southern Mozambique, Horak, Braack, Fourie \& Walker (2000) recorded 15 ixodid tick species on 13 species of wild carnivores. Haemaphysalis leachi and $R$. simus were amongst the most numerous of the adult ticks collected from these animals. Elsewhere in South Africa Bryson, Horak, Höhn \& Louw (2000) collected ticks from 
dogs belonging to people in resource-limited communities in North West Province. Many of these dogs were either caged or chained within the confines of their owners' properties and Rhipicephalus sanguineus was the most numerous of the six species present. Jacobs, Fourie, Kok \& Horak (2001) collected ticks from dogs in households in affluent and in resource-limited communities in and around the city of Bloemfontein, Free State Province, South Africa, and recorded significantly more $R$. sanguineus on dogs in the latter than in the former localities.

The South African surveys indicated that caged or chained dogs, or dogs owned by urban householders are more likely to be infested with $R$. sanguineus than those on larger properties, whereas those kept under more extensive conditions on small-holdings or farms, are liable to be infested with $H$. leachi and $R$. simus. Although the latter two species are also common on wild carnivores, no $R$. sanguineus have been collected from these animals (Horak et al. 2000). This survey was initiated to determine the species spectrum of ticks infesting domestic dogs in and around the city of Maputo as well as further afield in Mozambique, and whether there were differences in the species composition of the tick burdens of dogs in the city compared to those of dogs at rural settlements. In addition the geographic coordinates of each locality at which ticks were collected were recorded.

\section{MATERIALS AND METHODS}

Ticks were collected from 58 dogs in households in eight suburbs of the city of Maputo, and 16 collections were taken from dogs that were allowed to roam freely at three rural settlements around Maputo. Amongst the latter are six collections made at different times from the same dog at Goba, but listed separately. Five collections were also taken from dogs allowed to range freely at Sabié a rural settlement north-west of Maputo, and ten from dogs in provinces north of Maputo Province. Amongst the latter are four collections made from the same dog at Luala, Zambezia Province and a single collection made from this dog when it and its owners moved to Praia de Xai-Xai, Gaza Province.

All visible ticks were collected from each dog and placed in separate labelled vials containing $70 \%$ ethyl alcohol, thereafter the body surface of the dog was palpated and all ticks detected in this manner were collected and placed in the same vials as the visual collections. The ticks were initially sorted, identified and counted under a stereoscopic microscope at the Veterinary Faculty, University Eduardo Mondlane, in Maputo and their identities confirmed at the Faculty of Veterinary Science, University of Pretoria, South Africa.

\section{RESULTS AND DISCUSSION}

The geographic coordinates of the collection localities and the tick species collected at each locality are summarized in Table 1. Seven species were collected from the dog at Goba and five species each from dogs in the city of Maputo and at the Boane rural settlement.

The species and total numbers of ticks collected from dogs at all localities combined are summarized in Table 2, and the numbers of $H$. leachi and $R$. sanguineus collected either from city or from dogs at rural settlements in southern Maputo Province are compared in Table 3.

Ten tick species, of which one was only identified to genus level, were collected from the dogs. Four $(6.9 \%)$ of the 58 dogs examined in the city of Maputo were infested with $H$. leachi and 55 (94.8\%) with $R$. sanguineus. In the rural settlements around Maputo $15(93.8 \%)$ of the 16 collections contained $H$. leachi and three $(18.8 \%) R$. sanguineus. The intraspecific and the interspecific prevalence of both tick species at the two localities differed significantly $(P<0.01)$ (Fisher's Exact test). In addition, the intensity of infestation of $H$. leachi on dogs at rural settlements around the city of Maputo was significantly greater than that on dogs within the city, while the converse was true for $R$. sanguineus $(P<0.01)$ (Wilcoxon Rank sum test). Furthermore, the intensity of infestation of $R$. sanguineus on city dogs was significantly higher than that of $H$. leachi on the same group of dogs, whereas the converse was true for dogs in rural settlements $(P<0.01)$.

\section{Amblyomma spp.}

An A. hebraeum larva was collected from a single dog at Malhangalene in the city of Maputo, and larvae and/or nymphs of this tick were collected from dogs at the rural settlements of Goba and Sabié as well as at Save in Manica Province. A larva and the nymphs of an Amblyomma sp. were present on dogs at Malhangalene and at the rural settlement of Chiango. The immature stages of $A$. hebraeum and Amblyomma marmoreum and probably other species of Amblyomma readily infest domestic dogs that are allowed to roam freely and also wild carni- 
TABLE 1 Localities in Mozambique at which ticks were collected from dogs

\begin{tabular}{|c|c|c|}
\hline Locality & Coordinates & Tick species \\
\hline \multicolumn{3}{|l|}{ City of Maputo } \\
\hline $\begin{array}{l}\text { Dalo } \\
\text { Ferroviario } \\
\text { Laulane } \\
\text { Luis Cabral } \\
\text { Malhangalene } \\
\text { Militin } \\
\text { Polana Caniço } \\
\text { Polana Cimento }\end{array}$ & 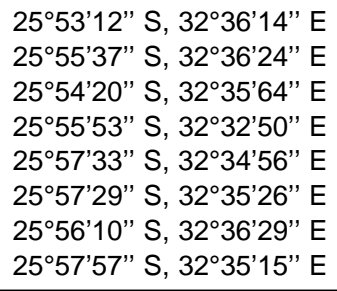 & $\begin{array}{l}\text { A. hebraeum, Amblyomma sp., H. leachi, R. sanguineus, } \\
\text { R. simus }\end{array}$ \\
\hline \multicolumn{3}{|c|}{ Rural settlements around the city of Maputo } \\
\hline $\begin{array}{l}\text { Boane } \\
\text { Chiango } \\
\text { Goba }\end{array}$ & $\begin{array}{l}26^{\circ} 04^{\prime} 18^{\prime \prime} \text { S, } 32^{\circ} 20^{\prime} 20^{\prime \prime} E \\
25^{\circ} 54^{\prime} 33^{\prime \prime} \text { S, } 32^{\circ} 39^{\prime} 36^{\prime \prime} \text { E } \\
26^{\circ} 03^{\prime} 59^{\prime \prime} \text { S, } 32^{\circ} 10^{\prime} 25^{\prime \prime} E\end{array}$ & $\begin{array}{l}\text { H. leachi, H. spinulosa, } R . \text { sanguineus, R. simus, R. turanicus } \\
\text { Amblyomma sp., H. leachi } \\
\text { A. hebraeum, H. leachi, H. spinulosa, R. (Boophilus) microplus, } \\
\text { R. pravus group, R. simus, R. turanicus }\end{array}$ \\
\hline \multicolumn{3}{|l|}{ Maputo Province } \\
\hline Sabié & $25^{\circ} 16^{\prime} 22^{\prime \prime} \mathrm{S}, 32^{\circ} 14^{\prime} 24^{\prime \prime} \mathrm{E}$ & A. hebraeum, H. leachi \\
\hline \multicolumn{3}{|l|}{ Gaza Province } \\
\hline Praia de Xai-Xai & $25^{\circ} 06^{\prime} 33^{\prime \prime} \mathrm{S}, 33^{\circ} 34^{\prime} 48^{\prime \prime} \mathrm{E}$ & H. leachi \\
\hline \multicolumn{3}{|l|}{ Manica Province } \\
\hline $\begin{array}{l}\text { Matthews' home } \\
\text { Save }\end{array}$ & $\begin{array}{l}20^{\circ} 10^{\prime} 08^{\prime \prime} \mathrm{S}, 33^{\circ} 13^{\prime} 15^{\prime \prime} \mathrm{E} \\
21^{\circ} 16^{\prime} 55^{\prime \prime} \mathrm{S}, 33^{\circ} 19^{\prime} 14^{\prime \prime} \mathrm{E}\end{array}$ & $\begin{array}{l}\text { H. leachi, H. spinulosa, R. simus } \\
\text { A. hebraeum }\end{array}$ \\
\hline \multicolumn{3}{|c|}{ Zambezia Province } \\
\hline Luala & $17^{\circ} 44^{\prime} 11^{\prime \prime} \mathrm{S}, 36^{\circ} 15^{\prime} 26^{\prime \prime} \mathrm{E}$ & H. leachi, H. spinulosa, R. sanguineus, $R$. tricuspis \\
\hline
\end{tabular}

TABLE 2 Ticks in 89 collections from dogs in Mozambique

\begin{tabular}{|l|l|l|r|r|r|r|}
\hline \multirow{2}{*}{ Tick species } & \multicolumn{2}{l|}{ Total number of ticks collected } & \multicolumn{2}{l|}{$\begin{array}{l}\text { No. of } \\
\text { collections }\end{array}$} \\
\cline { 2 - 7 } & Larvae & Nymphs & Males & Females & Total & \\
\hline Amblyomma hebraeum & 11 & 22 & 0 & 0 & 33 & 7 \\
Amblyomma sp. & 1 & 4 & 0 & 0 & 5 & 3 \\
Haemaphysalis leachi & 0 & 31 & 115 & 111 & 257 & 29 \\
Haemaphysalis spinulosa & 0 & 0 & 3 & 6 & 9 & 4 \\
Rhipi. (Boophilus) microplus & 0 & 0 & 0 & 1 & 1 & 1 \\
Rhipicephalus pravus group & 0 & 0 & 0 & 1 & 1 & 1 \\
Rhipicephalus sanguineus & 0 & 68 & 799 & 617 & 484 & 62 \\
Rhipicephalus simus & 0 & 0 & 47 & 36 & 3 & 19 \\
Rhipicephalus tricuspis & 0 & 0 & 0 & 13 & 22 & 4 \\
Rhipicephalus turanicus & 0 & 0 & 9 & & \\
\hline
\end{tabular}

vores (Horak, Jacot Guillarmod, Moolman \& De Vos 1987; Horak et al. 2000, 2001). However, the presence of an $A$. hebraeum larva and the immature stages of an Amblyomma sp. on dogs in the suburb of Malhangalene is difficult to explain because in
Africa the adults of most species of this genus feed on cattle, or other large herbivorous animals (Petney, Horak \& Rechav 1987), that are unlikely to be found in a city suburb. However, Malhangalene differed in other respects from the other suburbs of 
Ixodid ticks on dogs in Mozambique

TABLE 3 Haemaphysalis leachi and Rhipicephalus sanguineus on dogs in the city of Maputo and in surrounding rural settlements

\begin{tabular}{|c|c|c|c|c|c|c|c|}
\hline \multicolumn{8}{|c|}{ Species and number of ticks collected } \\
\hline \multicolumn{3}{|c|}{ Haemaphysalis leachi } & \multirow{2}{*}{$\begin{array}{l}\text { Positive } \\
\text { collections }\end{array}$} & \multicolumn{3}{|c|}{ Rhipicephalus sanguineus } & \multirow{2}{*}{$\begin{array}{l}\text { Positive } \\
\text { collections }\end{array}$} \\
\hline Nymphs & Adults & Total & & Nymphs & Adults & Total & \\
\hline \multicolumn{8}{|c|}{ Maputo city } \\
\hline 0 & 6 & $6^{\mathrm{A}}$ & $4 / 58^{C}$ & 54 & 1391 & $1445^{B}$ & $55 / 58^{\mathrm{D}}$ \\
\hline \multicolumn{8}{|c|}{ Rural settlements around Maputo } \\
\hline 30 & 137 & $167^{A}$ & $15 / 16^{C}$ & 0 & 5 & $5^{\mathrm{B}}$ & $3 / 16^{\mathrm{D}}$ \\
\hline
\end{tabular}

Items in the same column with the same superscript differ significantly $(P<0.01)$

Maputo in that the dogs there were also infested with adult $R$. simus, a tick usually encountered on dogs in rural areas (Horak et al. 1987, 2001).

\section{Haemaphysalis spp.}

Dogs in three suburbs of the city of Maputo and also at rural settlements in Maputo and other provinces were infested with $H$. leachi, and dogs at Boane, Goba, the Matthews' homestead and at Luala with Haemaphysalis spinulosa. Adult $H$. leachi are parasites of dogs, jackals (Canis spp.) and the large wild cats such as cheetahs, Acinonyx jubatus, lions, Panthera leo, leopards, Panthera pardus as well as African civets, Civettictis civetta (Norval 1984; Horak et al. 1987, 2000, 2001). Although the immature stages may use dogs as hosts (Horak et al. 1987), they prefer burrow-dwelling rodents (Norval 1984). The life cycle is sustained by the rodent/carnivore host complex (Norval 1984; Horak et al. 2000), and this could account for the high prevalence of $H$. leachi on dogs in the rural areas and their scarcity in the city.

\section{Rhipicephalus (Boophilus) microplus}

This tick is a parasite of cattle and its occurrence on other hosts is probably dependent on the presence of cattle as maintenance hosts. In KwaZulu-Natal $266 R$. (B.) microplus were collected from a goat compared to an average burden of 16346 on two calves examined at the same time at the same diptank area (Baker \& Ducasse 1968). Its presence on a dog in the rural environment of Goba can probably be ascribed to the fact that this animal was used to muster a herd of goats at a locality in which there was also cattle.

\section{Rhipicephalus spp.}

All developmental stages of $R$. sanguineus prefer domestic dogs as hosts to the virtual exclusion of all other animals (Walker et al. 2000), and its life cycle is adapted to man-made structures such as human dwellings and dog kennels (Howell, Walker \& Nevill 1978). Consequently it is particularly prevalent in cities or townships where dogs are chained, caged or confined to the properties of their owners (Bryson et al. 2000), as is the case in the city of Maputo. It was also present on three of the nine dogs examined at the rural settlement of Boane. The presence of $R$. sanguineus on dogs in the seaboard city of Maputo is to our knowledge the first time that it has been recorded close to an ocean in southern Africa.

This observation, taken in conjunction with those of various surveys conducted inland, implies that provided dogs are kept confined to small properties, or are chained or kennelled, the possibility exists that they can sustain populations of $R$. sanguineus at any locality within the region. The dog examined on four occasions at Luala, Zambezia Province was infested both with $R$. sanguineus and $H$. leachi. This dog lived in the home of its owners, where it was likely to have acquired infestation with the former tick, but also accompanied them into rural areas, where it probably acquired infestation with the latter.

The single $R$. pravus-group tick was taken from a dog at Goba, a host species on which, and a region in which ticks of this group have previously been recorded (Walker et al. 2000). Its immature stages feed on elephant shrews, Elephantulus spp., and all stages of development feed on scrub hares, Lepus saxatilis. It is particularly prevalent on the latter ani- 
mals in the northern regions of the Kruger National Park, South Africa to the west of southern Mozambique (Horak, Spickett, Braack, Penzhorn, Bagnall \& Uys 1995).

The immature stages of the remaining three species of Rhipicephalus feed on rodents, hence the prevalence of their adults on dogs at rural settlements where rodents are likely to occur. However, nine of the 12 dogs examined at Malhangalene, Maputo city were infested with adult $R$. simus, indicating an abundance of rodent hosts for its immature stages. Malhangalene straddles the transition between an urban suburb and a shantytown and the probability of a large rodent population in the latter locality cannot be excluded. Rhipicephalus simus was also present on dogs in the rural settlements of Boane and Goba as well as at the Matthews homestead in Manica Province.

One collection from the dog at Luala contained three female $R$. tricuspis, a tick that has previously been recorded on a dog in Mozambique (Dias 1993). Its preferred hosts appear to be steenbok, Rhaphicerus campestris, spring hares, Pedetes capensis and hares, Lepus spp. (Walker et al. 2000).

Rhipicephalus turanicus was present on a dog at Boane and on the dog at Goba. Although there appear to be only three locality records for $R$. turanicus in Mozambique (Walker et al. 2000), it has been collected from dogs and scrub hares in northeastern KwaZulu-Natal, to the south, and from wild carnivores and from the vegetation in the Kruger National Park, to the west (Horak et al. 1995, 2000, 2001). The four collections from dogs in this survey are from localities that lie between these regions.

\section{ACKNOWLEDGEMENTS}

We are grateful to all the dog owners who co-operated with the collection of ticks from their animals. Ticks were collected from dogs in and around the city of Maputo with the assistance of Messrs D.G. Mathe, J.M. Saúte and A. Dominguês, from dogs in Manica Province by Prof. N. Donkin and students of the Faculty of Veterinary Science, University of Pretoria, and by Mr and Ms G.J. Bester at different times from their dog in Zambezia and Gaza Provinces. We much appreciate the assistance of Dr J. Nöthling of the Faculty of Veterinary Science, University of Pretoria with the statistical analysis of the data.

\section{REFERENCES}

BAKER, MAUREEN K. \& DUCASSE, F.B.W. 1968. Tick infestation of livestock in Natal. The role played by goats as reservoirs of the economically important cattle ticks. Journal of the South African Veterinary Medical Association, 39:55-59.

BRYSON, N.R., HORAK, I.G., HÖHN, E.W. \& LOUW, J.P. 2000. Ectoparasites of dogs belonging to people in resource-poor communities in North West Province, South Africa. Journal of the South African Veterinary Association, 71:175-179.

CAMICAS, J.-L., HERVY, J.-P., ADAM, F. \& MOREL, P.C. 1998. The ticks of the world (Acarida, Ixodida). Nomenclature, described stages, hosts, distribution. Paris: Orstom éditions.

DIAS, J.A., TRAVASSOS SANTOS. 1960. Lista das carraças de Moçambique e respectivos hospedeiros. III. Anais dos Serviços de Veterinária e Indústria Animal de 1953-1954, No. 6:213-287.

DIAS, J.A., TRAVASSOS SANTOS. 1993. Some data concerning the ticks (Acarina-Ixodoidea) presently known in Mozambique. Garcia de Orta, Séries Zoologica, Lisboa, 18 (1991): 27-48.

HORAK, I.G., JACOT GUILLARMOD, AMY, MOOLMAN, L.C. \& DE VOS, V. 1987. Parasites of domestic and wild animals in South Africa. XXII. Ixodid ticks on domestic dogs and on wild carnivores. Onderstepoort Journal of Veterinary Research, 54:573-580.

HORAK, I.G., SPICKETT, A.M., BRAACK, L.E.O., PENZHORN, B.L., BAGNALL, R.J. \& UYS, A.C. 1995. Parasites of domestic and wild animals in South Africa. XXXIII. Ixodid ticks on scrub hares in the north-eastern regions of Northern and Eastern Transvaal and of KwaZulu-Natal. Onderstepoort Journal of Veterinary Research, 62:123-131.

HORAK, I.G., BRAACK, L.E.O., FOURIE, L.J. \& WALKER, JANE B. 2000. Parasites of domestic and wild animals in South Africa. XXXVIII. Ixodid ticks collected from 23 wild carnivore species. Onderstepoort Journal of Veterinary Research, 67:239-250.

HORAK, I.G., EMSLIE, F.R. \& SPICKETT, A.M. 2001. Parasites of domestic and wild animals in South Africa. XL. Ticks on dogs belonging to people in rural communities and carnivore ticks on the vegetation. Onderstepoort Journal of Veterinary Research, 68:135-141.

HOWELL, C.J., WALKER, JANE B. \& NEVILL, E.M. 1978. Ticks, mites and insects infesting domestic animals in South Africa. Part 1. Descriptions and biology. Department of Agricultural Technical Services, Republic of South Africa. (Science Bulletin no. 393).

JACOBS, P.A.H., FOURIE, L.J., KOK, D.J. \& HORAK, I.G. 2001. Diversity, seasonality and sites of attachment of adult ixodid ticks on dogs in the central region of the Free State Province, South Africa. Onderstepoort Journal of Veterinary Research, 68:281-290.

NORVAL, R.A.I. 1984. The ticks of Zimbabwe. IX. Haemaphysalis leachi and Haemaphysalis spinulosa. Zimbabwe Veterinary Journal, 15:9-17.

PETNEY, T.N., HORAK, I.G. \& RECHAV, Y. 1987. The ecology of the African vectors of heartwater, with particular reference to Amblyomma hebraeum and Amblyomma variegatum. Onderstepoort Journal of Veterinary Research, 54:381-395.

THEILER, GERTRUD. 1943. Notes on the ticks off domestic stock from Portuguese East Africa. Estação Anti-Malárica de Lourenço Marques: Imprensa Nacional de Moçambique.

WALKER, JANE B., KEIRANS, J.E. \& HORAK, I.G. 2000. The genus Rhipicephalus (Acari, Ixodidae): a guide to the brown ticks of the world. Cambridge: Cambridge Academic Press. 